\title{
Chain Conformation and Crystallization Behavior of the Syndiotactic Polystyrene Nanocomposites Studied Using Fourier Transform Infrared Analysis
}

\author{
Hew-Der Wu, Chen-Rui Tseng, and Feng-Chih Chang* \\ Institute of Applied Chemistry, National Chiao-Tung University, Hsin-Chu, Taiwan, 30043 \\ Received November 9, 1999; Revised Manuscript Received May 19, 2000
}

\begin{abstract}
Analyses of the effects of montmorillonite (clay) on the chain conformation and crystallization of syndiotactic polystyrene (s-PS) thin films are investigated using FTIR spectroscopy, X-ray diffraction, and TEM. The clay is dispersed into the s-PS matrix using a solution blending with scale in $1-2 \mathrm{~nm}$ or in a few tenths to $100 \mathrm{~nm}$, depending on whether a surfactant is added or not. Upon adding clay, the chain conformation of s-PS tends to convert to TTTT from TTGG after drying because the highly dispersed clay overcomes the energy barrier of chain conformation transformation. This phenomenon leads to a change in a conventional mechanism of molecular packing for s-PS in the drying stage. During meltcrystallization, clay plays a vital role in facilitating the formation of the thermodynamically favored alltrans $\beta$ form crystal, particularly on the s-PS thin film samples. When the s-PS is melt-crystallized at a cooling rate of $1^{\circ} \mathrm{C} / \mathrm{min}$ from $320^{\circ} \mathrm{C}$, the highest absolute crystallinity of $\beta$ form up to 0.56 occurs in the clay dispersibility of few tenths to $100 \mathrm{~nm}$ in the s-PS matrix; then dispersibility is of $1-2 \mathrm{~nm}(0.49)$, and the final one is of pure s-PS (0.42). Evidently, clay significantly affects the chain conformation and crystallization of s-PS.
\end{abstract}

\section{Introduction}

The highly stereoregular syndiotactic polystyrene (sPS) has received considerable interest recently. Depending on the thermal history, s-PS possesses several polymorphic crystalline structures. Helical (TTGG) conformation is formed in solution recovered S-PS, whereas the thermodynamically favored all-trans (TTTT) conformations are formed from either the melt or the annealing at an elevated temperature. ${ }^{1-6}$ The extent to which thermal history affects the crystalline structure and crystallization kinetics for s-PS has been extensively studied. ${ }^{7-10}$

Blending thermoplastic polymers with montmorillonite (clay) has also attracted increasing interest owing to its ability to substantially improve overall mechanical properties, optical properties, and magnetic behavior when a slight amount of clay is dispersed within a polymer matrix. ${ }^{11-15}$ Although blends of thermoplastic polymer and clay are typically incompatible, the clay is well dispersed in nanometer scale in a polymer matrix if suitable organically modified clay is used. ${ }^{16}$ Thus, as expected, the clay dispersibility within a polymer matrix depends on the type and quantity of surfactant employed. However, lesser attention has been paid to how clay, in a manner similar to that of nucleating agents, affects the chain conformation and polymorphic crystalline structure of polymers.

Having been extensively applied to characterize polymer, ${ }^{17}$ FTIR spectroscopy complement other techniques in providing detailed information on the chain conformation transition and crystallinity of a polymer with nondestructive and fast feature. ${ }^{2,18-20}$ The changes of chain conformation and crystallinity can be characterized by identifying FTIR spectral features of intensity, bandwidth, and position.

\footnotetext{
* To whom all correspondence should be addressed. E-mail: changfc@cc.nctu.edu.tw.
}

In this study, SEM and X-ray diffraction are used to identify the clay dispersibility within the s-PS matrix. Solid-state FTIR is applied to characterize the changes of chain conformation and of crystallinity in claycontained s-PS. The thickness of s-PS film is less than $10 \mu \mathrm{m}$ to minimize the extent to which thickness affects the crystallization of s-PS. Two goals are pursued: (1) detailed characterization of chain conformation and morphology of s-PS caused by clay dispersibility in drying stage and (2), more importantly, examining the effect of clay dispersibility on crystallinity of s-PS thin film samples during melt-crystallization. The observed chain conformation and morphology provide valuable information regarding the effect of clay on crystallization of s-PS.

\section{Experimental Section}

Materials. The syndiotactic polystyrene (s-PS) was synthesized using a homogeneous catalyst consisting of $\mathrm{CpTiCl}_{3}$ and methylalumoxane (MAO) in toluene, ${ }^{3}$ with $M_{n}=100000$. The chemical structure of the s-PS with $[\mathrm{rr}]=99 \%$ has been identified by the solution ${ }^{13} \mathrm{C}$ NMR spectrum. ${ }^{13}$ The montmorillonite "Kunipia F" (clay) was supplied by the Kunimine Co. of J apan. This clay mineral bears exchangeable sodium ions with exchange capacity of ca. 119 mequiv per $100 \mathrm{~g}$. Cetylpyridium chloride (CPC), a cationic surfactant, was purchased from Sigma with purity greater than $99 \%$.

Preparation of Organophilic Clay Mineral. Sodium montmorillonite $(1 \mathrm{~g}), 0.39 \mathrm{~g}$ of CPC, and $50 \mathrm{~mL}$ of distilled water were placed in a $100 \mathrm{~mL}$ beaker with equivalent ratio of clay:CPC = 1:1. The mixture was stirred vigorously for $8 \mathrm{~h}$ and then filtered, washed, freeze-dried, and kept in a vacuum oven at room temperature for $24 \mathrm{~h}$. This organically modified clay (denoted as "clay/CPC" in following text) was found to be hydrophobic.

Preparation of s-PS/Clay Hybrids. The well-dried and predetermined S-PS powder and clay or clay/CPC were added into dichlorobenzene in suitable concentration and then stirred at $140{ }^{\circ} \mathrm{C}$ for $24 \mathrm{~h}$.

Apparatus and Procedures. Sample Preparation and Infrared Spectra. The s-PS thin film and bulk samples were 


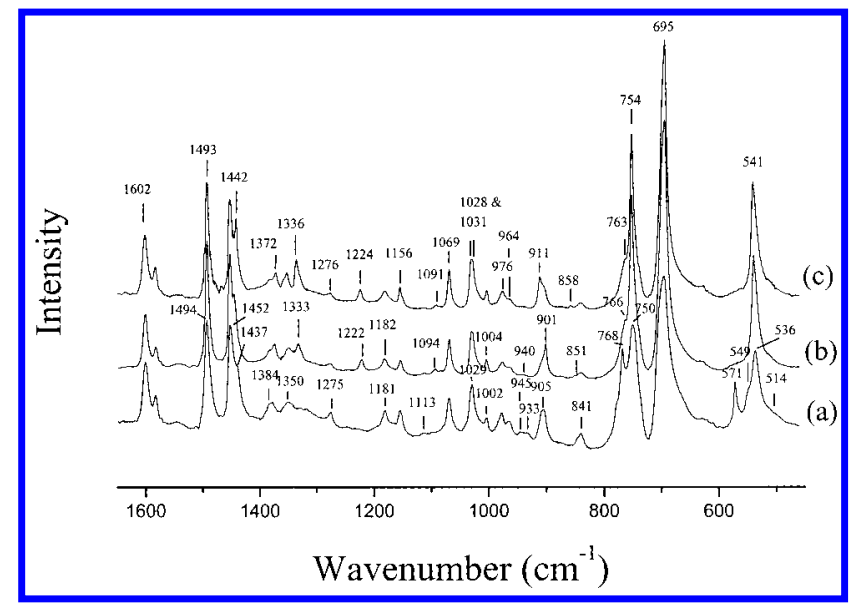

Figure 1. FTIR spectra of s-PS ranging from 1650 to 450 $\mathrm{cm}^{-1}$ : (a) amorphous; (b) $\alpha$ form; (c) $\beta$ form.

prepared by solution casting on a $\mathrm{KBr}$ disk by controlling its thickness less than $10 \mu \mathrm{m}$ and more than $100 \mu \mathrm{m}$, respectively. Both samples were drying in a vacuum at $140^{\circ} \mathrm{C}$ for $24 \mathrm{~h}$ and then followed by covering with another $\mathrm{KBr}$ disk before further thermal treatment. The isothermal experiments were carried out in an environmental chamber with a temperatureprogrammable controller to an accuracy of $\pm 0.1{ }^{\circ} \mathrm{C}$. The thermal treatment procedures for s-PS hybrid were carried out by preheating at $320^{\circ} \mathrm{C}$ for $20 \mathrm{~min}$ and then cooled at a desired cooling rate before recorded spectra. Different cooling rates were employed to prepare various s-PS hybrids that can reduce the error from the unstable temperature control for an isothermal treatment on the fast crystallizable s-PS. All thermal treatment processes were carried out under continuous nitrogen flow to ensure minimal sample oxidation or degradation.

I nfrared spectra were obtained at a resolution of $1.0 \mathrm{~cm}^{-1}$ with FTIR (Nicolet AVATAR $320 \mathrm{FTIR}$ spectrometer, U.S.A.) at $30{ }^{\circ} \mathrm{C}$ ranging from 4000 to $400 \mathrm{~cm}^{-1}$. The frequency scale was internally calibrated using a $\mathrm{He}-\mathrm{Ne}$ laser, and 32 scans were signal-averaged to reduce the noise.

Wide-AngleX-ray Diffration. X-ray diffraction spectra were collected on a X-ray diffraction instrument (M 18XHF-SRA., MacScience Co., J apan), using the $\mathrm{Co} \mathrm{K} \alpha$ radiation, and Bragg's law $(\lambda=2 d \sin \theta)$ was used to compute the spacing.

Transmission Electron Microscopy (TEM). A TEM micrograph was taken from a microtomed section of the s-PS/clay hybrid of 60-100 nm thickness and mounted in epoxy using a TEM (J EM-2000FX, J oel Co. J apan) with an acceleration voltage of $100 \mathrm{kV}$

\section{Results and Discussion}

IR Characterization of S-PS. S-PS has received considerable interest owing to its pluralistic crystallizations in recent years. ${ }^{1,2,5,6,9}$ Four distinct polymorphs $(\alpha$, $\beta, \gamma$, and $\delta$ ) have been identified, ${ }^{9}$ which can be divided into two groups: (i) $\gamma$ and $\delta$ forms possessing a helical trans-trans and gauche-gauche (TTGG) chain conformation and (ii) $\alpha$ and $\beta$ forms possessing a planar alltrans (TTTT) "zigzag" conformation. Notably, the desired crystal must be prepared to correlate the characteristic absorbance in the FTIR spectrum with a specific chain conformation and crystal forms. Figure 1 shows the FTIR spectra ranging from 1650 to $480 \mathrm{~cm}^{-1}$ of s-PS in amorphous, $\alpha$, and $\beta$ forms, as prepared according to a procedure described el sewhere. ${ }^{2,9}$ I $\mathrm{n}$ the following, we describe the FTIR vibrational spectroscopic features with respect to variation of the s-PS crystalline structure as based on reported literature ${ }^{2-4,18}$ and our observations:
The insensitive peaks of s-PS are 1602, 1452, 1384, 1350,1113 , and $976 \mathrm{~cm}^{-1}$.

Amorphous peaks are 1494, 1437, 1377, 1275, 1181, $1154,1079,1069,1029,1002,964,945,933,905,841$, 768, 750, and 538 (TTTT) and 536 (TTGG) cm ${ }^{-1}$.

The main zigzag ( $\alpha$ and $\beta$ ) peaks are 1493 (shifted from $1494 \mathrm{~cm}^{-1}$ ), 1276 (shifted from $1275 \mathrm{~cm}^{-1}$ ), 1156, 1069, 1031, and 1028 (splitted from $1029 \mathrm{~cm}^{-1}$ ), 964, and $940 \mathrm{~cm}^{-1}$.

The specific peaks of $\alpha$ form are 1445 (shifted from $1437 \mathrm{~cm}^{-1}$ ), 1374 (shifted from $1377 \mathrm{~cm}^{-1}$ ), 1333, 1222, 1182 (shifted from $1181 \mathrm{~cm}^{-1}$ ), 1094 and 1083 (spitted from $1079 \mathrm{~cm}^{-1}$ ), 1004 (shifted from $1002 \mathrm{~cm}^{-1}$ ), 901 (shifted from $905 \mathrm{~cm}^{-1}$ ), $851 \mathrm{~cm}^{-1}$ (shifted from 841 $\left.\mathrm{cm}^{-1}\right), 766$, and $751 \mathrm{~cm}^{-1}$.

The specific peaks of $\beta$ form are 1442 (shifted from $1437 \mathrm{~cm}^{-1}$ ), 1372 (shifted from $1377 \mathrm{~cm}^{-1}$ ), 1336, 1224, 1182 (shifted from $1181 \mathrm{~cm}^{-1}$ ), 1091 and 1086 (shifted from $1079 \mathrm{~cm}^{-1}$ ), 1003 (shifted from $1002 \mathrm{~cm}^{-1}$ ), 911 (shifted from $905 \mathrm{~cm}^{-1}$ ), 858 (shifted from $841 \mathrm{~cm}^{-1}$ ), 763 , and $754 \mathrm{~cm}^{-1}$

The frequency in the range $600-500 \mathrm{~cm}^{-1}$ reflects the local skeletal conformation in the neighborhood of the phenyl group. The amorphous spectrum contains a main peak at $536 \mathrm{~cm}^{-1}$, and two partially resolved absorbances appear at 571 and $514 \mathrm{~cm}^{-1} .21$ Absorbances at 571,536 , and $514 \mathrm{~cm}^{-1}$ are assigned to TTGG conformations and the absorbance at $548 \mathrm{~cm}^{-1}$ is assigned to the GTTG conformation. The $541 \mathrm{~cm}^{-1}$ absorbance is characteristic of the TTTT chain conformation in the crystal structure while the $538 \mathrm{~cm}^{-1}$ is in the amorphous structure.

Morphologies of s-PS/Hybrid Composites. Parts $a$ and $b$ of Figure 2 show the thin section TEM micrographs of s-PS/clay/CPC $=95 / 5 / 5$ (by weight, as in following text) and S-PS/clay $=95 / 5$ hybrids after drying, respectively. Figure $2 a$ reveals that the TEM bright field image of s-PS/clay/CPC hybrid, where the clay layers (dark line, less than $2 \mathrm{~nm}$ width) are distributed evenly. The CPC surfactant accommodates the intercalated clay by the organic cation and renders the hydrophobic silicate surface organophilic. 22 Figure $2 \mathrm{~b}$ indicates that the untreated clay within the S-PS matrix is not so well dispersed, the exfoliated layers of clay are present, and the clay disperses in the range of $a$ few tenths to $100 \mathrm{~nm}$. The clay layers in Figure $2 \mathrm{~b}$ are relatively rougher and more agglomerated than those in Figure $2 a$.

On the other hand, morphology reveals that both samples did not apparently change after isothermal at $320{ }^{\circ} \mathrm{C}$ for $20 \mathrm{~min}$, which was followed by cooling at a rate of $1{ }^{\circ} \mathrm{C} / \mathrm{min}$. The clay dispersibility within the s-PS matrix remains unchanged after further thermal treatment.

$X$-ray diffraction patterns provide further evidence of clay dispersibility in s-PS matrix. Parts $a, b, c$, and d of Figure 3 present X-ray diffraction patterns for the pure clay, $\beta$ form s-PS crystal, s-PS/clay $=95 / 5$, and s-PS/ day $/ C P C=95 / 5 / 5$ hybrids ranging from $2 \theta=3^{\circ}$ to $10^{\circ}$, respectively. Both s-PS hybrids were obtained by quenching in liquid nitrogen from $320^{\circ} \mathrm{C}$; meanwhile, the pure $\beta$ form s-PS crystal was obtained on the basis of previous literature.2,9 The X-ray diffraction pattern of pure clay contains basal reflections that are characteristic of an unintercalated repeated distance of $d=1.2 \mathrm{~nm} \mathrm{(} 2 \theta=$ $7.1^{\circ}$ ) as shown in Figure 3a. A sharp peak appearing at $2 \theta=6.1^{\circ}$ (Figure $3 \mathrm{~b}$ ) corresponds to $\beta$ form s-PS 


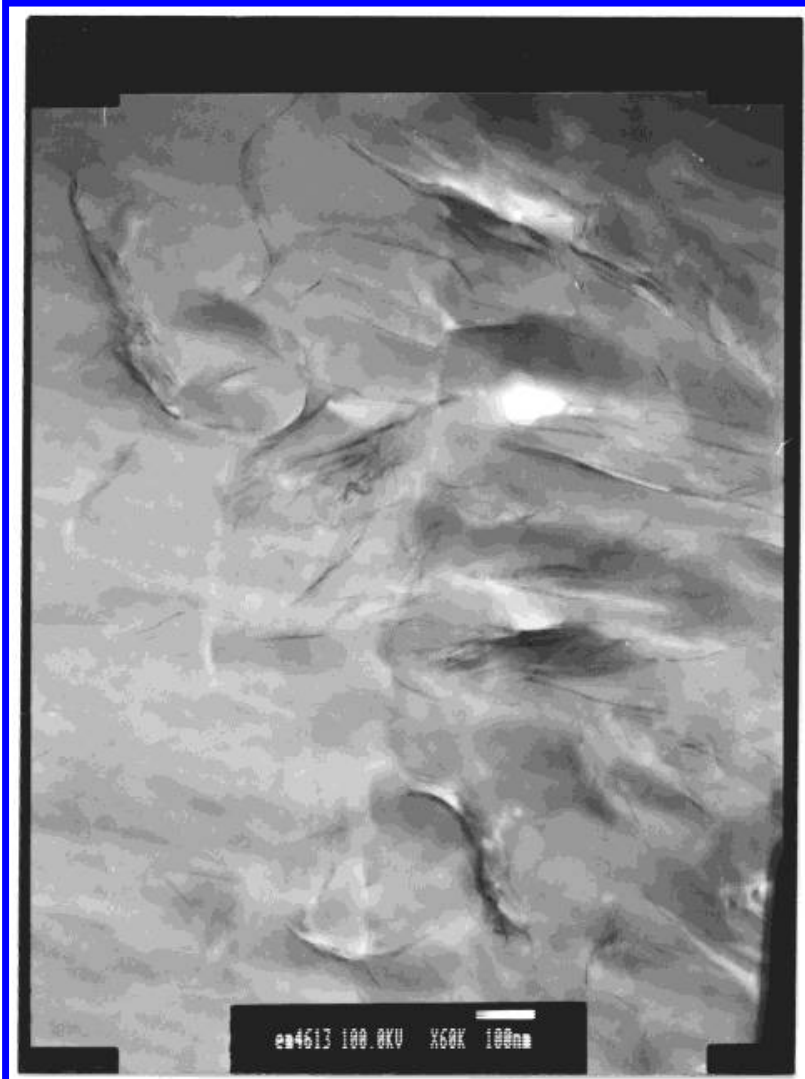

(a)

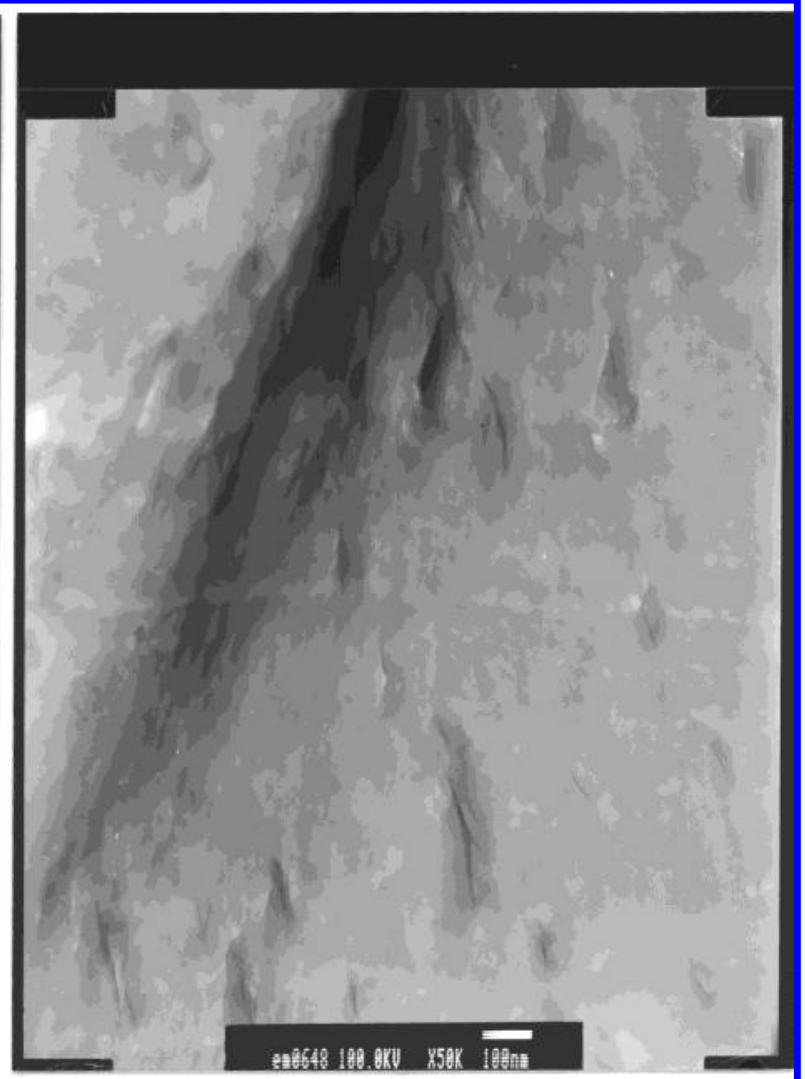

(b)

Figure 2. TEM micrographs of thin sections of (a) s-PS/clay/CPC $=95 / 5 / 5(\times 60 \mathrm{~K})$ and (b) s-PS/clay $=95 / 5(\times 50 \mathrm{~K})$ hybrid obtained from solution without thermal treatment.

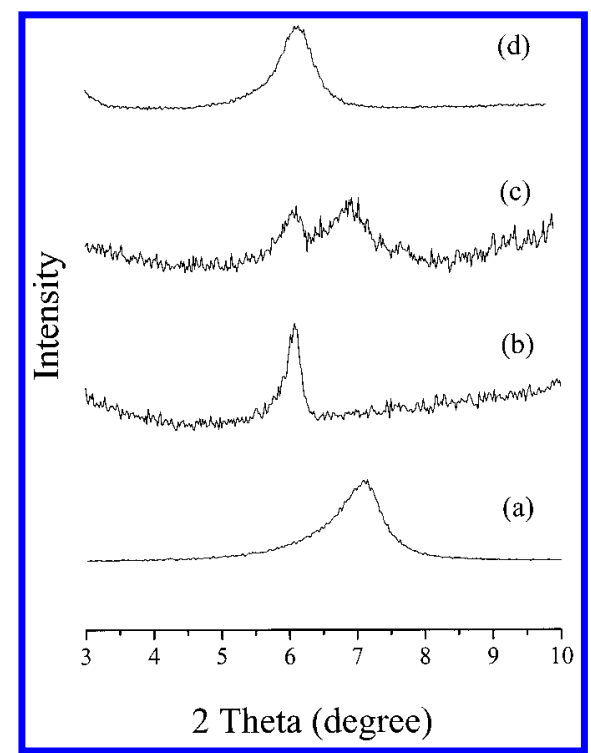

Figure 3. X-ray diffraction patterns ranging from $2 \theta=3^{\circ}$ to $10^{\circ}$ for (a) pure clay, (b) pure $\beta$ form of S-PS, (c) s-PS/clay $=$ $95 / 5$, and (d) s-PS/clay/CPC $=95 / 5 / 5$. Pure $\beta$ form s-PS prepared from the literature. 2,9 The s-PS hybrids in (c) and (d) were obtained by quenched by liquid nitrogen from $320^{\circ} \mathrm{C}$.

crystal .5,6,9,23,24 Two peaks appearing at $2 \theta=6.9^{\circ}$ and $6.1^{\circ}$ (Figure 3c) correspond to the swelled clay and the $\beta$ form s-PS crystal in the S-PS/clay hybrid. Only one wide peak appearing at $2 \theta=6.1^{\circ}$ (Figure 3d) corresponds to the $\beta$ form s-PS crystal. Moreover, the X-ray diffraction pattern of clay disappears completely in the measured range in Figure $3 c, d$, implying that the clay

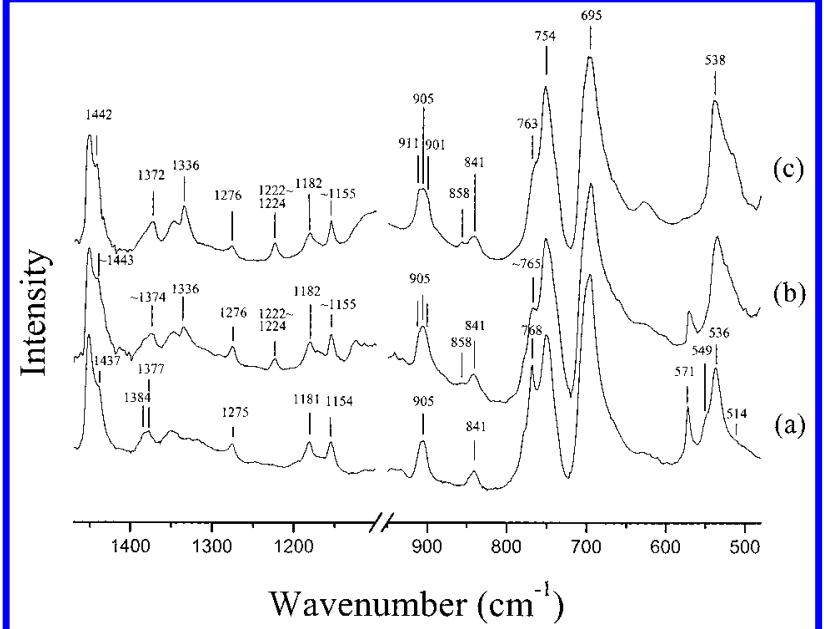

Figure 4. FTIR spectra from 1475 to $1100 \mathrm{~cm}^{-1}$ and 950 to $480 \mathrm{~cm}^{-1}$ of untreated (a) s-PS, (b) s-PS/clay $=95 / 5$, and (c) s-PS/clay/CPC $=95 / 5 / 5$ hybrids, prepared from solution.

delaminates completely within the s-PS matrix when clay is pretreated by the CPC surfactant.

The TEM images and the X-ray diffraction patterns confirm the presence of clay upon mixing with s-PS in nanoscale. In addition, the clay dispersi bility within the S-PS matrix depends on whether CPC is added or not.

Clay Effects on the Chain Conformation. Figure 4 shows the FTIR spectra of the untreated S-PS, S-PS/ clay, and s-PS/clay/CPC hybrids ranging from 1474 to $1100 \mathrm{~cm}^{-1}$ and 950 to $480 \mathrm{~cm}^{-1}$. This figure reveals that the intensity and position in FTIR spectra vary due to 


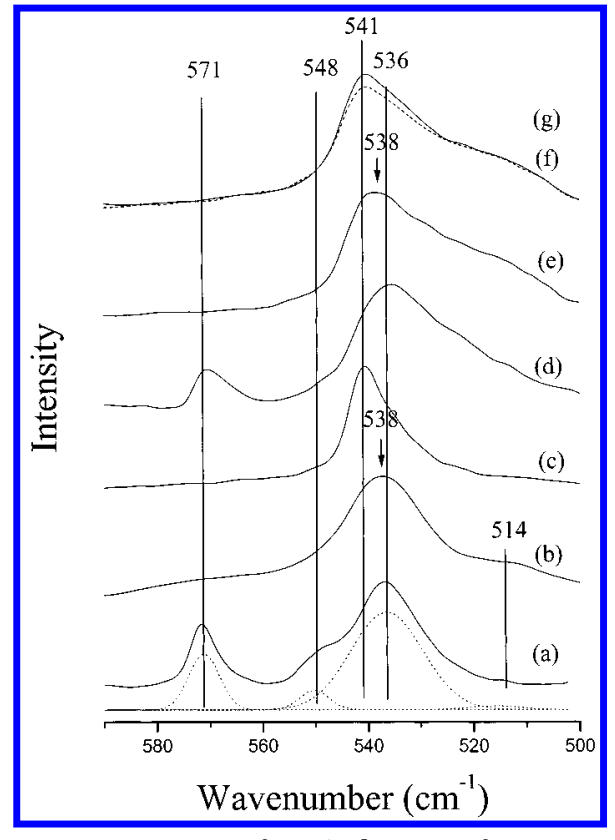

Figure 5. FTIR spectra of s-PS chain conformation ranging from 590 to $500 \mathrm{~cm}^{-1}$ that have been through various thermal treatments. Pure s-PS (a) without thermal treatment, (b) annealed at $320{ }^{\circ} \mathrm{C}$ for $20 \mathrm{~min}$ and quenched by LN, (c) annealed at $320{ }^{\circ} \mathrm{C}$ for $20 \mathrm{~min}$ and cooling rate $1{ }^{\circ} \mathrm{C} / \mathrm{min}$; without thermal treatment for (d) s-PS/clay $=95 / 5$, (e) s-PS/ clay/CPC = 95/5/5; annealed at 320 for $20 \mathrm{~min}$ and cooling rate $1{ }^{\circ} \mathrm{C} / \mathrm{min}$ for (f) s-PS/clay/CPC $=95 / 5 / 5$ (dashed line), (g) s-PS/clay $=95 / 5$ hybrid (dotted line represents the deconvoluting result of Figure $5 \mathrm{a}$ ).

the nature of change in s-PS induced by adding either clay or clay/CPC. From the appearance of the $571 \mathrm{~cm}^{-1}$ peak and the absence of the $1222-1224 \mathrm{~cm}^{-1}$ peak in Figure 4a, we can infer that the TTGG chain conformation associated with the amorphous phase is obtained when the solvent is expelled from the s-PS. ${ }^{8}$ A small $1222-1224 \mathrm{~cm}^{-1}$ peak appears in Figure 4b,c, while the peak at $571 \mathrm{~cm}^{-1}$ gradually decreases with an increase of clay dispersibility. The crystal is formed after drying while clay is dispersed in a few nanometers within the s-PS matrix.

Figure 5 illustrates the FTIR spectra of s-PS chain conformation ranging from 590 to $500 \mathrm{~cm}^{-1}$ for the neat s-PS and its hybrids that have underwent various thermal treatments. Preliminary deconvoluted analysis of the experimental amorphous profile (Figure 5a, as obtained from drying) reveals four distinct components centered at 571, 548, 536, and $514 \mathrm{~cm}^{-1}$. These components reflect the concurrent presence of the above local chain conformation, TTGG and GTTG, in the amorphous phase. Notably, the isolated TTTT segment on s-PS cannot be formed without mutual cooperation of adjacent chains in a 3-D space on the basis of the results of molecular modeling. ${ }^{19}$ In general, the thermal treatment provides the energy required for the s-PS chain conformation transformation. Figure $5 b$ shows the FTIR spectrum of s-PS that was isothermal at $320{ }^{\circ} \mathrm{C}$ for 20 min and then quenched by liquid nitrogen. The peak at $538 \mathrm{~cm}^{-1}$, which shifted from $536 \mathrm{~cm}^{-1}$, corresponds to TTTT amorphous s-PS. Although nearly disappearing, three other absorbances at 514, 548, and $571 \mathrm{~cm}^{-1} \mathrm{can}$ still be observed, implying that some of the TTTT sequences may still be bound to either TT or GG sequences. Therefore, not all of the TTGG and GTTG conformations have transformed into the TTTT. Figure $5 c$ presents the FTIR spectrum of s-PS which has been isothermal at $320^{\circ} \mathrm{C}$ for $20 \mathrm{~min}$ and then crystallized nonisothermally using a slow cooling rate of $1^{\circ} \mathrm{C} / \mathrm{min}$. These peaks corresponding to TTGG and GTTG chain conformations have now completely disappeared, while the main peak corresponding to crystalline TTTT chain conformation is sharpened and shifts completely to 541 $\mathrm{cm}^{-1}$. Undoubtedly, the TTTT becomes the only discernible chain conformation in the s-PS crystal.

The development of 3D crystalline order in S-PS is favored both thermodynamically and kinetically in crystallization. 1,2,25,26 The chain conformation change of s-PS is irreversible, and the kinetics of phase transition is nonequilibrium in nature. ${ }^{9,20}$ Therefore, the chain conformation, orientation, and overall morphology of the neat s-PS crystal before and after thermal treatment shown in Figure 5a-c provide preliminary information on the magnitude and position of the peak to further compare between s-PS/clay and s-PS/clay/CPC hybrids.

Parts $d$ and e of Figure 5 show the FTIR spectra of s-PS/clay and s-PS/day/CPC hybrids without thermal treatment, respectively. A main peak appears at 536 $\mathrm{cm}^{-1}$ in the untreated s-PS/clay hybrid (Figure $5 \mathrm{~d}$ ). Although peaks appear at 548 and $571 \mathrm{~cm}^{-1}$, their intensities are relatively lower than pures-PS as shown in Figure 5a. I nterestingly, the component at $541 \mathrm{~cm}^{-1}$ begins to emerge initially. This finding implies that, although chain conformations of TTGG and GTTG are dominant, certain TTTT chain conformations and crystals are formed in s-PS/clay hybrid after drying. Figure 5e shows that the peaks at 548 and $571 \mathrm{~cm}^{-1}$ disappear completely while the main component shifts to $538 \mathrm{~cm}^{-1}$ in s-PS/clay/CPC hybrid after drying. The fraction of the $541 \mathrm{~cm}^{-1}$ peak in Figure 5 e is relatively higher than that in Figure $5 \mathrm{~d}$. The TTTT chain conformation (including the 541 and $538 \mathrm{~cm}^{-1}$ ) is the unique conformation in the s-PS/clay/CPC hybrid. Its crystallinity is higher than that in S-PS/clay hybrid, which is also higher than the pure s-PS after drying.

Comparing the variety in the FTIR range of 590-500 $\mathrm{cm}^{-1}$ in Figure $5 a, b, d, e$ and the appearance of the 1224$1222 \mathrm{~cm}^{-1}$ peak in Figure 4b,c reveals that the clay dispersibility in the s-PS matrix affects not only on the collaborative rotation of bonds along the s-PS chain but also on the molecular reorder. ${ }^{26}$ Notably, clay (or clay/ CPC) in the s-PS matrix not only enhances the "zigzag" chain conformation but also acts as a "nucleus" to induce crystal formation. s-PS with a higher clay dispersibility provides more "nudei" to form higher molecular orientation. Therefore, we can refer that the presence of the clay is able to overcome the transition energy barrier to TTTT from TTGG chain conformation after drying. Thus, the TTTT chain conformation induces the initial molecular reorder to form crystals.

Upon cooling at a rate of $1{ }^{\circ} \mathrm{C} / \mathrm{min}$ after isothermal at $320{ }^{\circ} \mathrm{C}$, the $541 \mathrm{~cm}^{-1}$ peak is sharper, reflecting a higher degree of molecular order in the TTTT chain conformation in both s-PS/clay/CPC and s-PS/clay hybrids, as shown in Figure $5 f$ (dashed line) and Figure $5 \mathrm{~g}$ (solid line), respectively. Interestingly, $541 \mathrm{~cm}^{-1}$ in Figure $5 f$ is relatively weaker than that in Figure $5 g$, implying that the "zigzag" crystalline fraction is greater in the s-PS/clay hybrid than that in the s-PS/clay/CPC hybrid. However, this tendency is contradictory to the corresponding hybrids without thermal treatment.

Effects of Clay on Crystal Form and Crystallinity. The trace of crystal forming along with the thermal history for the s-PS sample can be drawn using the 


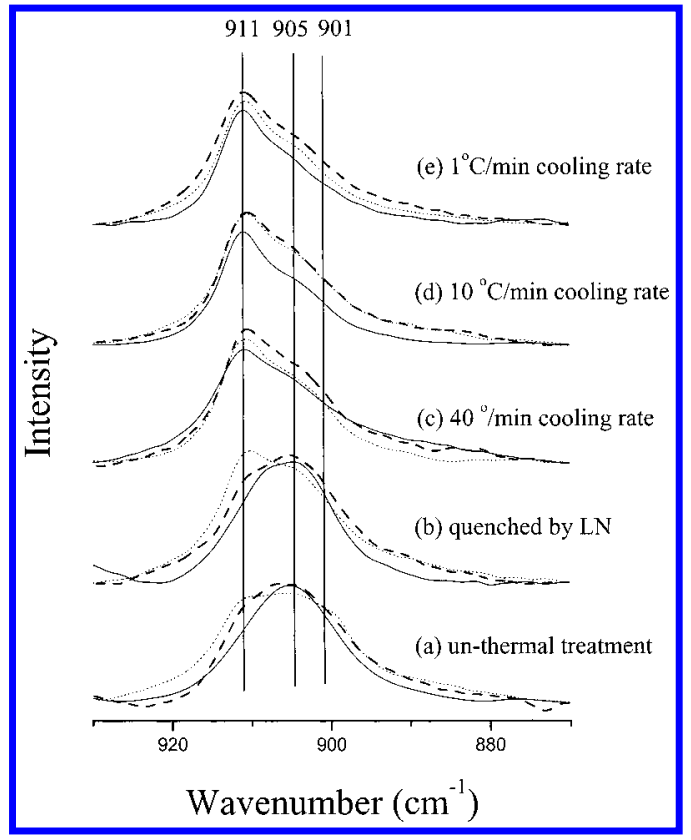

Figure 6. FTIR spectra ranging from 930 to $870 \mathrm{~cm}^{-1}$ of pure s-PS (solid line), s-PS/clay = 95/5 (dashed line), and s-PS/clay/ CPC $=95 / 5 / 5$ (dotted line) hybrids. (a) Untreated; (b) annealed at $320{ }^{\circ} \mathrm{C}$ for $20 \mathrm{~min}$ and quenched by L N ; (c) annealed at 320 ${ }^{\circ} \mathrm{C}$ for $20 \mathrm{~min}$ and cooled at a rate of $40^{\circ} \mathrm{C} / \mathrm{min}$; (d) annealed at $320^{\circ} \mathrm{C}$ for $20 \mathrm{~min}$ and cooled at a rate of $10{ }^{\circ} \mathrm{C} / \mathrm{min}$; (e) annealed at $320^{\circ} \mathrm{C}$ for $20 \mathrm{~min}$ and cooled at a rate of $1^{\circ} \mathrm{C} /$ $\min$.

FTIR spectra. Figure 6 shows the FTIR spectra of pure s-PS, s-PS/clay, and s-PS/clay/CPC hybrids by different thermal treatments ranging from 930 to $870 \mathrm{~cm}^{-1}$, in a range highly sensitive to chain packing. These samples have been isothermal at $320{ }^{\circ} \mathrm{C}$ for $20 \mathrm{~min}$ and then cooled to ambient condition with various cooling rates. The sol id line represents the pure s-PS, the bulk dashed line represents the s-PS/clay, and dotted line represents the s-PS/clay/CPC hybrid. These spectral baselines have been offset to clearly indicate changes throughout the different thermal histories. The peak position and intensity of the $1602 \mathrm{~cm}^{-1}$ peak (corresponding to benzene ring, as shown in Figure 1) remains unaffected by varying either the chain conformation or crystallinity in these s-PS FTIR spectra. All peak areas in the range that have been normalized are referred to in the 1602 $\mathrm{cm}^{-1}$ peak area. This provides an efficient and reliable means of identifying and quantifying the crystal forms present in a s-PS sample.

Three peaks are particularly important in this region 911,905 , and $901 \mathrm{~cm}^{-1}$, corresponding to $\beta$ form crystal, amorphous phase, and $\alpha$ form crystal, respectively. According to our results, the exact wavenumber and shape of the peak depend on the clay dispersibility and thermal history. The solid lines in parts $a$ and $b$ of Figure 6 illustrate the FTIR spectra of pure s-PS after drying and after quenching by liquid nitrogen, respectively. A single peak at $905 \mathrm{~cm}^{-1}$ is found in Figure $6 a, b$ solid lines, implying that only the amorphous phase is present in pure s-PS after drying or after quenching by liquid nitrogen. There are two additional peaks at 911 and $901 \mathrm{~cm}^{-1}$ (shifted from $905 \mathrm{~cm}^{-1}$ ) which appear in s-PS/clay and s-PS/clay/CPC hybrids as shown by dashed and dotted lines of Figure $6 a$, b. It is pronounced, especially for the s-PS/clay/CPC hybrids where the clay dispersibility is known better. The thin film sample of this hybrid with highly dispersive clay enhances the all-

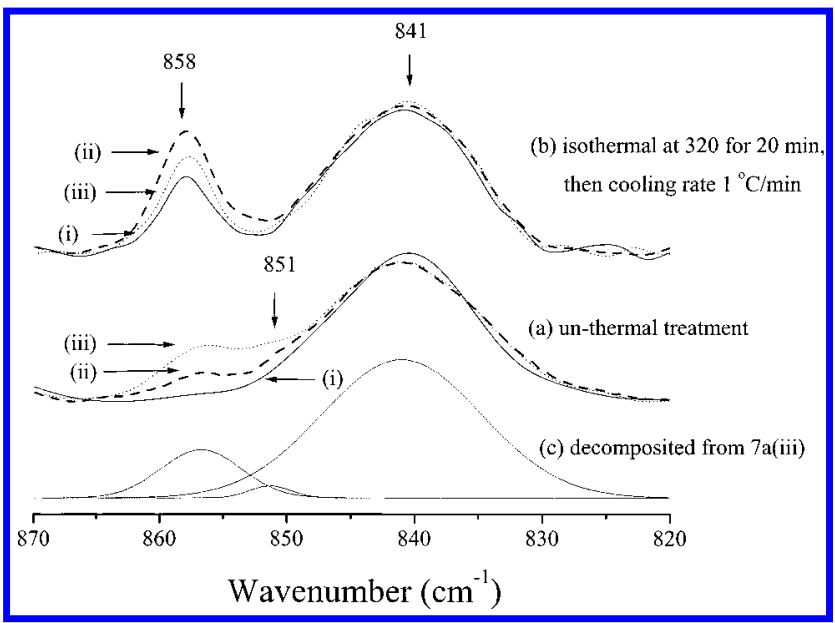

Figure 7. FTIR spectra ranging form 865 to $820 \mathrm{~cm}^{-1}$ of various S-PS hybrids. (a) Untreated (i) pure s-PS (solid line), (ii) s-PS/clay $=95 / 5$ (dashed line), and (iii) s-PS/clay/CPC = 95/5/5 (dotted line). (b) Annealed at $320^{\circ} \mathrm{C}$ for $20 \mathrm{~min}$ and cooled at a rate of $1{ }^{\circ} \mathrm{C} / \mathrm{min}$ for (i) pure s-PS (solid line), (ii) s-PS/clay = 95/5 (dashed line), and (iii) s-PS/clay/CPC = 95/ $5 / 5$ (dotted line). (c) Result of deconvoluting from Figure 7a (iii).

trans planar structure that is associated with the formation of $\alpha$ and $\beta$ crystals phases in the drying stage.

The $\beta$ form peak grows gradually which is associated with decreasing the amorphous phase by reducing the cooling rate for neat s-PS, s-PS/clay, s-PS/clay/CPC hybrids as shown in Figure 6, c, d, and e. The strongest $\beta$ form peak occurs at the sample of s-PS/clay, but not at the better clay dispersed s-PS/clay/CPC hybrid at the cooling rate of $1 \mathrm{~min} /{ }^{\circ} \mathrm{C}$.

Parts $a$ and $b$ of Figure 7 show the FTIR spectra of s-PS, s-PS/clay, and s-PS/clay/CPC ranging from 865 to $820 \mathrm{~cm}^{-1}$ for untreated and isothermal at $320^{\circ} \mathrm{C}$ for 20 min and, then, cools at a rate of $1{ }^{\circ} \mathrm{C} / \mathrm{min}$, respectively. The solid line represents the pure s-PS, the bulk dashed line represents the s-PS/clay, and the dotted line represents the s-PS/clay/CPC hybrid. These spectral baselines have also been offset to more clearly indicate the changes caused by adding clay or clay/CPC. All areas of the $841 \mathrm{~cm}^{-1}$ peak in Figure 7 are normalized to make a quantitative comparison. Results obtained from deconvoluting in the range between 865 and 820 $\mathrm{cm}^{-1}$ indicate that three/two peaks allow for an adequate fit to the experimental data in parts $a$ and $b$ of Figure 7, respectively. Figure 7c provides an illustrative example which results from deconvoluting of Figure 7a (iii) (short dotted line). Table 1 summarizes the inte grated absorbance areas of $865-820 \mathrm{~cm}^{-1}$ after deconvoluting for various thermal histories.

The untreated s-PS possesses a single $841 \mathrm{~cm}^{-1}$ peak because only the amorphous phase is present. Upon adding clay, the $841 \mathrm{~cm}^{-1}$ peak shifts into two distinct components at 851 and $858 \mathrm{~cm}^{-1}$, corresponding to $\alpha$ and $\beta$ crystal forms as shown in Figures 7a (ii) and (iii). The intensity of both $\alpha$ and $\beta$ form peaks in s-PS/clay hybrid (Figure 7a (ii)) is considerably less than that of s-PS/day/CPC hybrid (Figure 7a (iii)). Along with the decreasing cooling rate, only the $\beta$ form crystal (858 $\left.\mathrm{cm}^{-1}\right)$ is found, while the $\alpha$ form crystal $\left(851 \mathrm{~cm}^{-1}\right)$ disappears completely as shown in Figure $7 \mathrm{~b}$. The absolute crystallinity of $\alpha$ and $\beta$ form can be calculated from the following equations: ${ }^{27}$ 
Table 1. Results of Curve Fitting from the Range $865-820 \mathrm{~cm}^{-1}$ for Pure s-PS, s-PS/Clay, and s-PS/Clay/CPC Hybrids

\begin{tabular}{|c|c|c|c|c|c|c|c|c|c|}
\hline \multirow[b]{3}{*}{ thermal history } & \multicolumn{9}{|c|}{ peak area of } \\
\hline & \multicolumn{3}{|c|}{ pures-PS } & \multicolumn{3}{|c|}{ s-PS/clay hybrid } & \multicolumn{3}{|c|}{ s-PS/clay/CPC hybrid } \\
\hline & $\begin{array}{l}\text { amorphous } \\
\left(\sim 841 \mathrm{~cm}^{-1}\right)\end{array}$ & $\begin{array}{c}\alpha \text { form } \\
(\sim 851 \\
\left.\mathrm{cm}^{-1}\right)\end{array}$ & $\begin{array}{l}\beta \text { form } \\
(\sim 858 \\
\left.\mathrm{cm}^{-1}\right) \\
\end{array}$ & $\begin{array}{l}\text { amorphous } \\
\left(\sim 841 \mathrm{~cm}^{-1}\right)\end{array}$ & $\begin{array}{c}\alpha \text { form } \\
\left(\sim 851 \mathrm{~cm}^{-1}\right)\end{array}$ & $\begin{array}{l}\beta \text { form } \\
(\sim 858 \\
\left.\mathrm{cm}^{-1}\right) \\
\end{array}$ & $\begin{array}{l}\text { amorphous } \\
\left(\sim 841 \mathrm{~cm}^{-1}\right)\end{array}$ & $\begin{array}{c}\alpha \text { form } \\
(\sim 851 \\
\left.\mathrm{cm}^{-1}\right)\end{array}$ & $\begin{array}{l}\beta \text { form } \\
(\sim 858 \\
\left.\mathrm{cm}^{-1}\right) \\
\end{array}$ \\
\hline unthermal treatment & 0.996 & 0.004 & & 0.930 & 0.010 & 0.060 & 0.864 & 0.019 & 0.107 \\
\hline quenched by LN & 0.998 & 0.002 & & 0.901 & 0.006 & 0.093 & 0.850 & & 0.141 \\
\hline $\begin{array}{l}\text { cooling rate of } \\
40^{\circ} \mathrm{C} / \mathrm{min}\end{array}$ & 0.909 & 0.002 & 0.089 & 0.809 & & 0.191 & 0.825 & & 0.175 \\
\hline $\begin{array}{l}\text { cooling rate of } \\
20^{\circ} \mathrm{C} / \mathrm{min}\end{array}$ & 0.881 & & 0.119 & 0.798 & & 0.202 & 0.820 & & 0.180 \\
\hline $\begin{array}{c}\text { cooling rate of } \\
10^{\circ} \mathrm{C} / \mathrm{min}\end{array}$ & 0.873 & & 0.127 & 0.783 & & 0.217 & 0.811 & & 0.189 \\
\hline $\begin{array}{c}\text { cooling rate of } \\
5^{\circ} \mathrm{C} / \mathrm{min}\end{array}$ & 0.862 & & 0.138 & 0.768 & & 0.232 & 0.804 & & 0.196 \\
\hline cooling rate of & 0.836 & & 0.164 & 0.748 & & 0.252 & 0.792 & & 0.208 \\
\hline
\end{tabular}

a Absorbance area ranging from 865 to $820 \mathrm{~cm}^{-1}$ assumed to be 1 .

$$
\begin{aligned}
& C_{\alpha}=\frac{A_{851} / a_{\alpha}}{A_{841}+A_{851} / a_{\alpha}+A_{858} / a_{\beta}} \\
& C_{\beta}=\frac{A_{858} / a_{\beta}}{A_{841}+A_{851} / a_{\alpha}+A_{858} / a_{\beta}}
\end{aligned}
$$

where $\mathrm{C}_{\alpha}$ and $\mathrm{C}_{\beta}$ represent the crystallinity of $\alpha$ and $\beta$ forms, respectively, and $A_{841}, A_{851}$, and $A_{858}$ are the area fractions of amorphous, $\alpha$, and $\beta$ forms ranging from 865 to $820 \mathrm{~cm}^{-1}$, respectively. The conversion coefficients $a_{\alpha}$ and $a_{\beta}$, the ratio of absorptive coefficients $A_{851} / A_{841}$ and $\mathrm{A}_{858} / \mathrm{A}_{841}$ for $\alpha$ and $\beta$ form crystal absorbance, are 0.178 and 0.272 as obtained from previous literature. ${ }^{27}$ Table 2 summarizes the absolute crystallinities of $\alpha$ form for s-PS, s-PS/clay, and s-PS/day/CPC samples obtained from different thermal treatments. The crystallinity of $\alpha$ form is substantially lower than that of $\beta$ form before thermal treatment in the thin film sample and converts completely into the $\beta$ form after melt-crystallization, particularly for the clay-containing s-PS.

Figure 8 illustrates that the relationship between absolute crystallinity of $\beta$ form and different thermal histories for s-PS, s-PS/clay, and s-PS/clay/CPC samples. The crystallinity of the $\beta$ form crystal appears to increase when decreasing the cooling rate. The highest absolute crystallinity is obtained from the s-PS/clay/CPC hybrid, the second is from the s-PS/clay hybrid, and the last one is from the neat s-PS in drying stage. However, after the melt-crystallization, the highest absolute crystallinity is obtained in the s-PS/clay, the second is in the s-PS/clay/CPC, and the last one is in the neat s-PS. Therefore, growth of $\beta$ form crystal does not depend only the clay dispersibility in melt-crystallization. Furthermore, the crystallinity of $\alpha$ form is rather insignificant throughout the crystallization in thin film s-PS samples. It is inferred that thin film s-PS hinders the formation of the "initial nucleus" to grow the kinetically favored $\alpha$ form crystal. ${ }^{27}$ Restated, the s-PS thin film sample tends to induce the formation of the thermodynamically favored $\beta$ form crystal in meltcrystallization as predicted by the packing model.22,23 Therefore, the presence of clay provides a new path to obtain the thermodynamically favored $\beta$ form crystal for s-PS.

In summary, the FTIR spectra clearly indicate that clay significantly affects the s-PS chain conformation and its related morphology. During the drying stage,
Table 2. Crystallinity of $\alpha$ Form for Pure s-PS, s-PS/Clay, and s-PS/Clay/CPC Hybridsa

\begin{tabular}{lccc}
\hline & \multicolumn{3}{c}{ crystallinity of $\alpha$ form } \\
\cline { 2 - 4 } \multicolumn{1}{c}{ thermal history } & pure s-PS & $\begin{array}{c}\text { s-PS/clay } \\
\text { hybrid }\end{array}$ & $\begin{array}{c}\text { s-PS/clay/ } \\
\text { CPC hybrid }\end{array}$ \\
\hline unthermal treatment & 0.013 & 0.028 & 0.047 \\
quenched by L N & 0.007 & 0.016 & 0 \\
cooling rate of $40^{\circ} \mathrm{C} / \mathrm{min}$ & 0.005 & 0 & 0 \\
cooling rate less than & 0 & 0 & 0 \\
$20^{\circ} \mathrm{C} /$ min & & & \\
a The full crystallinity is assumed to be 1. &
\end{tabular}

the highly dispersive clay tends to induce the formation of all-trans chain conformation, leading to the formation of both $\alpha$ and $\beta$ crystallites. In melt-crystallization, the formation of $\beta$ form is preferred if the s-PS contains clay. However, the highest crystallinity with the most perfect in chain orientation unexpectedly appears on s-PS/clay hybrid in which clay disperses in a few tenths to 100 $\mathrm{nm}$, instead of the better dispersed s-PS/clay/CPC hybrid.

Transitions among Various Chain Conformations and Crystal Forms in S-PS nanocomposite Samples. Certain transitions occur in s-PS in its nanocomposites. Figure 9 summarizes the various transitions induced by clay, where the solid arrow denotes the direction of transition, and the dashed arrow represents the thermal history or sample condition. The pure s-PS obtained from drying is amorphous with TTGG and GTTG chain conformations. As clay was added into the s-PS matrix, a certain fraction of TTGG chain conformation is retained, while the TTTT chain conformation and the crystal begin to appear after drying. When the day/CPC is added into the s-PS matrix, the TTGG disappears completely, subsequently converting into TTTT chain conformation.

Clay is essential to produce TTTT chain conformation after drying. The high clay dispersibility is able to overcome the transition energy barrier of TTGG to TTTT chain conformation. Similarly, when the s-PS sample is quenched by liquid nitrogen after isothermal at $320^{\circ} \mathrm{C}$ for $20 \mathrm{~min}$, the dispersed clay al so enhances the formation of TTTT chain conformation. Through bond rotation, the higher clay dispersion in s-PS matrix lowers the crystalline potential energy of s-PS chain in drying stage and in melt-crystallization. This finding suggests that the presence of clay changes the conventional mechanism of molecular packing for s-PS. 


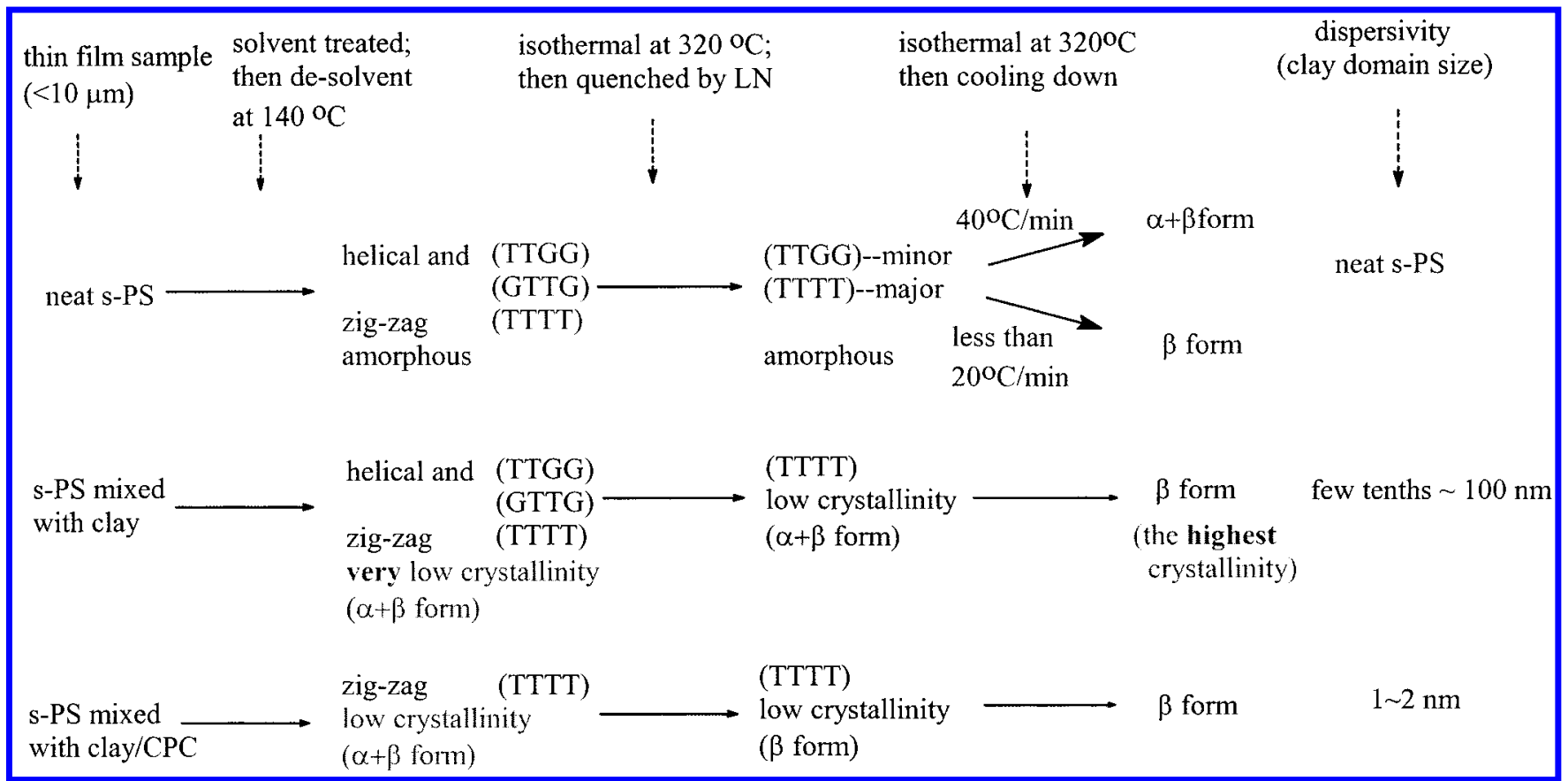

Figure 8. Relationship between absolute crystallinity and various thermal history: (a) neat s-PS, (b) s-PS/clay, and (c) s-PS/ clay/CPC hybrid.

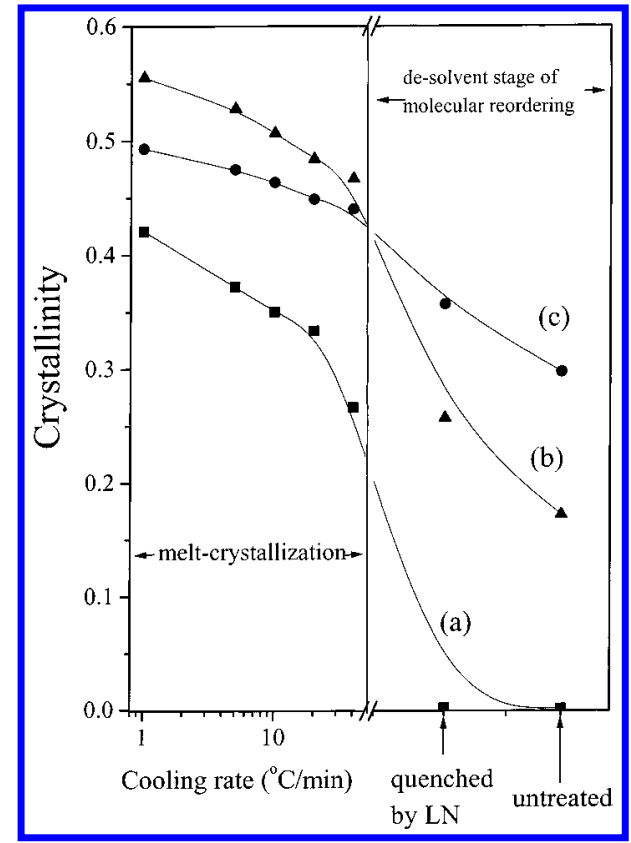

Figure 9. Various transitions made possible by adding clay into s-PS thin film nanocomposite sample.

Thin film s-PS samples prefer to form $\beta$ form crystal through melt-crystallization, ${ }^{27}$ particularly for claycontained s-PS. This observation emphasizes the vital role of clay in the formation of thermodynamically favored all-trans $\beta$ form crystal. However, the crystallinity and crystalline conversion rate are likely to be different for s-PS, s-PS/dlay, and s-PS/clay/CPC thin film samples in nonisothermal melt-crystallization. The sPS/clay hybrid with clay dispersibility in few tenths to $100 \mathrm{~nm}$ possesses the highest crystallinity, the second in the s-PS/clay/CPC with clay dispersibility in 1-2 nm, and the last one is the neat s-PS. Clay dispersibility does not appear solely determine the crystal perfection of $\beta$ form crystal in melt-crystallization; other factors must be also involved in this complex mechanism. An interesting question arises: What is the optimum "nucleus size" in prompting the highest crystallinity and the crystalline conversion rate? F urther work is underway in order to obtain more quantitative information on the "nucleus size" effects on s-PS crystallinity of the s-PS.

Regardless of mechanism involved, this study demonstrates that the clay addition does provide a new pathway to generate pure $\beta$ form crystal in s-PS matrix. This is desirable because the thermodynamically favored $\beta$ form crystal possesses better mechanical properties and solvent resistance. ${ }^{28-30}$

Acknowledgment. The authors thank the National Science Council, Taiwan, for financially supporting this research under Contract NSC-88-2116-E-009-006.

\section{References and Notes}

(1) Ishihara, N.; Seimiya, T.; Kuramoto, N.; U oi, M. Macromolecules 1986, 19, 2464.

(2) Kellar, E. J . C.; Galiotis, C.; Andrews, E. H. Macromolecules 1996, 29, 3515.

(3) Pellecchia, C.; Longo, P.; Grassi, A.; Ammendola, P.; Zambelli, A. Markromol. Chem. Rapid Commun. 1987, 8, 277.

(4) Musto, P.; Tavone, S.; Guerra, G.; De Rosa, C. L. Polym. Sci. Part B: Polym. Phys. 1997, 35, 1055.

(5) Woo, E. M.; Wu, F. S. Macromol. Chem. Phys. 1998, 199, 2041.

(6) Woo, E. M.; Wu, F. S. L. Polym. Sci., Part B: Polym. Phys. 1998, 36, 2725.

(7) Nakaoki, T.; Kobayashi, M. L. Mol. Struct. 1991, 242, 315.

(8) Reynolds, N. M.; Stidham, H. D.; Hsu, S. L. Macromol ecules 1991, 24, 3662.

(9) Guerra, G.; Vitagliano, V. M.; De Rosa, C.; Petraccone, V.; Corradini, P. Macromolecules 1990, 23, 1539.

(10) Kobayashi, M.; Nakaoki, T.; I shihara, N. Macromolecules 1989, 22, 4377.

(11) Waddell, W. H.; O'Haver, J . H.; Evans, L. R.; Harwell, J . H. L. Appl. Polym. Sci. 1995, 55, 1627.

(12) Godovski, D. Y.; Sukharev, V. Y.; Volkov, A. V. Phys. Chem. Solids 1993, 54, 1613.

(13) Wang, Y.; Herron, N. L. Phys. Chem. 1991, 95, 525.

(14) Yang, W. Opt. Commun. 1987, 61, 233.

(15) Kojima, Y.; Usuki, A.; Kawasumi, M.; Okada, A.; Kurauchi, T.; Kamigaito, O. L. Appl. Polym. Sci. 1993, 49, 1259.

(16) Tseng, C. R.; Wu, J . Y.; Lee, H. Y.; Chang, F. C., submitted.

(17) Strobl, G. R.; Hagedorn, W. L. Polym. Sci., Polym. Phys. Ed. 1978, 16, 1181. 
(18) Vittoria, V.; Ruvolo Filho, A.; De Candia, F. L. Macromol. Sci. Phys. 1990, B29, 411.

(19) Kellar, E. J. C.; Evan, A. M.; Knowles, J ; Galiotis, C.; Andrews, E. H. Macromolecules 1997, 30, 2400.

(20) Vittoria, V. Polym. Commun. 1990, 31, 263.

(21) Nakaoki, T.; Kobayashi, M. . Mol. Struct. 1991, 242, 315.

(22) Wu, H. D.; Wu, I. D.; Chang, F. C. Macromolecules 2000, 33, 8915.

(23) De Rosa, C.; Rapaccuolo, M.; Guerra, G.; Petraccone, V.; Corradini, P. Polymer 1992, 33, 1423.

(24) De Rosa, C.; Corradini, P. Macromol ecules 1993, 26, 5711.

(25) Doherty, D. C.; Hopfinger, A. L. Macromolecules 1989, 22, 2472.
(26) Wang, Y. K.; Savage, J . D.; Yang, D.; Hsu, S. L. Macromolecules 1992, 25, 3659.

(27) Wu, H. D.; Wu, I. D.; Chang, F. C. Polymer 2001, 42, 4719.

(28) Vittoria, V.; Russo, R.; de Candia, F. L. Macromol. Sci. Phys. 1989, B28, 419

(29) de Candia, F.; Romano, G.; Russo, R.; Vittoria, V. Colloid Polym. Sci. 1990, 268, 720 .

(30) Rapacciuolo, M.; de Rosa, C.; Guerra, G.; Mensitieri, G.; Apicella, A.; del Nobile, M. A. L. Mater. Sci., Lett. 1991, 10, 1084.

MA991897R 